\title{
Kinase insert domain receptor/vascular endothelial growth factor receptor 2 (KDR) genetic variation is associated with ovarian hyperstimulation syndrome
}

\author{
Travis J O'Brien ${ }^{*}$, Arthur F Harralson ${ }^{1,2}$, Tuyen Tran $^{3}$, lan Gindoff ${ }^{1}$, Funda E Orkunoglu-Suer ${ }^{4}$, David Frankfurter ${ }^{5}$ \\ and Paul Gindoff ${ }^{5}$
}

\begin{abstract}
Background: The objective of this investigation was to determine if kinase insert domain/vascular endothelial growth factor receptor 2 (KDR/VEGFR2) genetic variation was associated with the development of ovarian hyperstimulation syndrome (OHSS) in patients undergoing controlled ovarian hyperstimulation (COH).

Methods: This was a case-control study of 174 patients who underwent controlled ovarian stimulation. Patient blood samples were genotyped for single nucleotide polymorphisms (SNPs) spanning the KDR locus. OHSS development, clinical outcome variables, SNP and haplotype frequencies were compared between control $(n=155)$ and OHSS $(n=19)$ groups.

Results: Patients who developed OHSS had significantly higher response markers (estradiol levels of the day of hCG administration, number of follicles developed, number of eggs retrieved) than control patients. When adjusted for age and self-identified race, the rs2305945 $\mathrm{G} / T$ genotype was associated $(P=0.027)$ with a decreased risk $(\mathrm{OR}=0.30$; $95 \% \mathrm{Cl}=0.10,0.93)$ of developing OHSS using an overdominant model. The rs $2305945 \mathrm{G} / \mathrm{T}$ variant was also associated with decreased $\mathrm{COH}$ response (number of follicles, number of eggs retrieved) in an overdominant model. The rs2305948, rs1870378, rs2305945 (C-T-G) haplotype was associated with both decreased COH response and OHSS risk (unadjusted $\mathrm{OR}=0.10 ; 95 \% \mathrm{Cl}=0.01,0.80, \mathrm{P}=0.031$ ).

Conclusions: The KDR receptor is believed to play a central role OHSS development and is a target for pharmacological prevention of OHSS. These results indicate that genetic variation in the KDR gene may impact individual risk of developing OHSS from COH. In addition, the rs2305948 SNP and C-T-G haplotype might serve as potential biomarkers for poor ovarian response to $\mathrm{COH}$.
\end{abstract}

Keywords: Ovarian stimulation, Ovarian hyperstimulation syndrome, OHSS, KDR, VEGFR2, Polymorphism

\section{Background}

Controlled ovarian hyperstimulation $(\mathrm{COH})$ has played a leading role in improving outcomes from in vitro fertilization (IVF). The backbone of $\mathrm{COH}$ pharmacotherapy involves the use of exogenous gonadotropins. While there are several clinical predictors [1-4] of ovarian responsiveness that aid in individualizing $\mathrm{COH}[5,6]$, interindividual

\footnotetext{
* Correspondence: phmtjo@gwu.edu

'Department of Pharmacology and Physiology, The George Washington University, Washington, DC, USA

Full list of author information is available at the end of the article
}

variation in response to gonadotropin administration still exists. Additionally, patient risk of developing complications from $\mathrm{COH}$ is similarly unpredictable.

For the normal responder, $\mathrm{COH}$ is associated with some degree of risk for the iatrogenic complication ovarian hyperstimulation syndrome (OHSS). Potentially life threatening, OHSS leads to hospitalization in $1.9 \%$ of IVF cases [7]. Moderate to severe OHSS may be underestimated since many such cycles are frequently cancelled or result in the cryopreservation of all embryos [8]. Mild OHSS is relatively common with symptoms including abdominal

\section{Ciomed Central}


bloating and mild weight gain. OHSS is characterized by cystic enlargement of the ovaries, increased vascular permeability (VP) and movement of fluid from the peritoneal vasculature into the third space. Symptoms and signs of severe OHSS include dyspnea, hemoconcentration, diminished renal perfusion and thromboembolism $[9,10]$. In cases of severe OHSS, myocardial infarction and/or stroke can lead to death $[9,10]$. Early onset OHSS occurs within 3-5 days after oocyte retrieval and is related to the hyperresponse of the ovaries to $\mathrm{COH}$ followed by the use of hCG for oocyte maturation. Late onset OHSS appears 912 days after oocyte retrieval and results from $\mathrm{COH}$ and the endogenous hCG produced by a developing embryo [11]. Although rare, spontaneous cases of OHSS have been reported with the supra-physiologic hCG levels seen with multiple gestations or molar pregnancy [12]. Reports of familial spontaneous gestational OHSS suggest a genetic cause [13]. Regardless of severity, the development of OHSS is associated with significant physical, psychological and financial implications [14].

Standard practice emphasizes an avoidance approach in preventing OHSS (see below). There are several known risk factors for OHSS development that can assist in tailoring gonadotropin dosage [15-17]. In addition, markers for $\mathrm{COH}$ response (i.e. baseline anti-mullerian hormone $(\mathrm{AMH})$ levels, estradiol levels, intermediate follicle number and FSH levels) may serve as early indicators allowing corrective measures to be taken to decrease severity of OHSS. Specific preventative strategies include coasting, avoiding the use of hCG, delaying/reducing hCG administration or cryopreserving all embryos [18]. Unfortunately, beyond avoiding hCG for oocyte maturation, most current, proactive measures are not completely effective in preventing OHSS.

The molecular etiology of OHSS is unclear. Elevated serum estradiol [14], cytokine and interleukin levels have all been detected in the peritoneal fluid of women with OHSS [19,20]. Moreover, roles for renin-angiotensin, prolactin and prostaglandins in the increased VP observed during OHSS have also been proposed [21]. The most important VP factor in the ovaries is vascular endothelial growth factor (VEGF). In rats, VEGF mRNA levels and VP increased following gonadotropin stimulation [22] which was reversed by VEGF antiserum [23]. In humans, hCG administration increased VEGF expression in granulosa-lutein cells [24] and VEGF blood levels predicted the development of OHSS and its severity [25]. In addition, a single nucleotide polymorphism in the VEGF gene has been associated with increased OHSS risk [26]. Consequently, the prevailing model for OHSS development involves aberrant VEGF signaling as a key factor driving increased VP [23,27].

In the ovaries, VEGF-mediated VP, at least in part, is mediated by the kinase insert domain/vascular endothelial growth factor receptor 2 (KDR/VEGFR-2/Flk-1) signaling mechanisms [28-33]. In support of this, inhibition of both VEGF $[34,35]$ and KDR [22,31,32,35] has been shown to ameliorate VP development in models of OHSS. In addition, dopamine [36] and [37] dopamine receptor agonists [20,27,38-40] are known inhibit KDR function $[36,41]$ and show promise as both preventative and therapeutic options for OHSS [39,42-45].

Despite much research on the topic, very few predictive genetic biomarkers exist for $\mathrm{COH}$ outcome [46]. Genetic variation in FSHR [47], CYP19A1 [47], BMP15 [48], VEGF [26] and LHCGR [49] have all been associated with high response to $\mathrm{COH}$ and/or OHSS. KDR has been implicated in the etiology of OHSS and also serves as a target for pharmacotherapy $[20,38,40,45,50]$. However, no information is available on the association of KDR genetic variability and OHSS risk. As a result, the focus of this investigation was to evaluate the role of KDR polymorphisms in the development of OHSS.

\section{Methods}

This study was approved by George Washington University Institutional Review Board. Patients' and written informed consent was obtained prior to enrollment of patients (2010-2011). All IVF patients ( $>18$ years of age) who were treated at the GW Fertility and IVF Center with injectable gonadotropins were invited to participate. All patients were evaluated for ovarian reserve testing, semen analysis (male partner), uterine cavity study and thyroid screening. Controlled ovarian stimulation protocols were as previously described [49]. After initial follicular monitoring (serum estradiol and transvaginal ultrasound assessments), FSH dosing was titrated based upon the ovarian response. hCG trigger was withheld for E2 levels over $4000 \mathrm{pg} / \mathrm{ml}$ thus minimizing risk for OHSS. Both control and OHSS groups had similar risk factors including those identified at time of hCG trigger. Ovarian hyperstimulation syndrome was defined clinically based on established criteria [51,52]. For each patient the following clinical endpoints were recorded: estradiol level on day of hCG injection, number of ovarian follicles on day of hCG, number of follicles/follicles $>16 \mathrm{~mm}$ ), number of eggs retrieved and the incidence of OHSS.

For each patient, blood $(5 \mathrm{~mL})$ was collected and DNA was extracted using a QiaCube automated instrument with the QIAamp DNA Blood Mini Kit (Qiagen, Valencia, CA). KDR/VEGFR-2 SNPs rs3025035, rs2305948, rs2219471, rs1870378, rs2305945 and rs1870377 were genotyped using Real-Time PCR (TaqMan ${ }^{\circ}$ ). PCR was performed with a reaction volume of $10 \mu \mathrm{l}$, including $4.75 \mu \mathrm{l}$ of TaqMan $^{\circ}$ Universal PCR Master Mix, $0.5 \mu$ l of 20X DME Genotyping Assay Mix, $3.75 \mu$ of DEPC $\mathrm{H}_{2} \mathrm{O}$, and $1.0 \mu \mathrm{l}$ of genomic DNA. The PCR cycling conditions were as follows: 1 cycle of $50^{\circ} \mathrm{C}$ for 2 minutes, followed 
by 1 cycle of $95^{\circ} \mathrm{C}$ for 10 minutes and 50 cycles of $92^{\circ} \mathrm{C}$ for 15 seconds and $60^{\circ} \mathrm{C}$ for 90 seconds. Appropriate negative controls were included with each run. Allelic discrimination was carried out by measuring fluorescence intensity using an ABI 7300 Real Time PCR System (Applied Biosystems) and SDS software Version 1.3 (Applied Biosystems). PCR/sequencing primers are shown in Table 1. The genotype calls for each SNP were verified in subsets of samples by DNA sequencing as previously described [49] using PCR primers in Table 1.

Comparisons between OHSS and control samples for each of the clinical variables were conducted using SPSS (IBM, Armonk, NY). Due to the skewed nature of the data an independent samples Mann-Whitney $U$ test was used for all comparisons. SNPs spanning the KDR locus were selected using Haploview (version 4.2, $\mathrm{r}^{2}>0.75$ ) [53] (CEU population) [54]. Analyses for Hardy-Weinberg equilibrium, linkage disequilibrium (LD) and unadjusted odds ratios for OHSS risk were conducted using SNPSTATS [55] and HAPSTAT [56].

\section{Results}

We obtained genotypic and clinical information for 174 patients who underwent IVF. We have previously reported on the association of LHCGR rs4073366 C allele carrier status with OHSS $(\mathrm{n}=172)$ risk in this patient population [49]. However, we did not perform statistical comparisons of the control and OHSS populations' clinical characteristics. OHSS patients $(n=19)$ had significantly greater $\mathrm{COH}$ response markers than control patients $(\mathrm{n}=155)$. Specifically, estradiol $\left(E_{2}\right)$ levels (median; $25 \%, 75 \%$ percentile) on the day of hCG administration [Controls: $1735.0 \mathrm{pg} / \mathrm{mL}$ (1031.0-2280.0); OHSS: $2606.0 \mathrm{pg} / \mathrm{mL}$ (1996.0-3471.0)], number of follicles (median; $25 \%, 75 \%$ percentile) generated [Controls: 2.0 (1.0-4.0); OHSS: 5.0 (3.0-10.0)] and number of eggs (median; 25\%, 75\% percentile) retrieved [Controls: 8.0 (4.0-13.0); OHSS: 18.0 (13.0-26.0)] were all significantly $(\mathrm{P}<0.001)$ higher in OHSS patients. In addition, OHSS occurred to a greater extent in patients of self-identified Caucasian ethnicity versus Black, nonHispanic or Asian/Pacific Islander [49].

Six SNPs in the KDR gene were investigated for association with OHSS. SNPs were selected based on pairwise linkage disequilibrium analysis using HapMap [57] data (CEU population) in the KDR for the prediction of haplotype blocks. The 6 SNPs (rs3025035, rs2305948, rs2219471, rs1870378, rs2305945, rs1870377) spanning the KDR gene were selected and genotyped in both control and OHSS patients. SNPs that were not in Hardy Weinberg equilibrium (rs3025035, rs2219471, rs1870377) were omitted from further analysis. The remaining SNPs rs2305948, rs1870378 and rs2305945 were not in linkage disequilibrium (See Additional file 1: Table S1) and existed in 3 separate predicted haplotype blocks (data not shown). Specifically, tagged SNPs rs1870378 and rs2305945 included rs2219471 and rs6838752 (covering $\sim 5 \mathrm{~kb}$ ) and rs3828550 and rs13109660 (covering $\sim 5 \mathrm{~kb}$ ), respectively.

For rs2305948, C/C, C/T and $\mathrm{T} / \mathrm{T}$ variants occurred at frequencies of $0.75,0.23$ and 0.02 , respectively in the entire patient population (Table 2). The observed frequencies for rs $1870378 \mathrm{C} / \mathrm{C}, \mathrm{C} / \mathrm{T}$ and $\mathrm{T} / \mathrm{T}$ genotypes were $0.55,0.37$ and 0.07 of all patients in the study. The rs $2305945 \mathrm{G} / \mathrm{G}, \mathrm{G} / \mathrm{T}$ and $\mathrm{T} / \mathrm{T}$ variants were found at frequencies of $0.40,0.45$ and 0.14 in the total population as well. Although there were differences in the frequencies of SNPs in OHSS case versus control patients, none reached statistical significance (alpha of 0.05).

None of the individual SNPs were independent predictors (unadjusted) of OHSS risk (data not shown). In an overdominant model, rs23205945 was associated $(\mathrm{P}=$ $0.031)$ with decreased OHSS risk $(\mathrm{OR}=0.30 ; 95 \% \mathrm{CI}=$ $0.10,0.93)$ when corrected for age and self-identified race (Table 3). When adjusted for age $(\mathrm{P}=0.017)$, race $(\mathrm{P}=$ $0.017)$ or both age and race $(\mathrm{P}=0.013)$, the rs $2305945 \mathrm{G} / \mathrm{T}$ genotype was significantly associated with fewer follicles generated by $\mathrm{COH}$ (See Additional file 2: Table S2). In addition, the rs2305945 G/T genotype was marginally associated $(\mathrm{P}=0.046)$ with a fewer number of eggs retrieved in an overdominant model only after adjustment for selfidentified race (See Additional file 3: Table S3).

A significant difference in haplotype distribution between OHSS cases and control patients $(\mathrm{P}=0.033)$ was observed. Interestingly, one (rs2305948, rs1870378, rs2305945; T-T$\mathrm{T}$ ) of the eight possible haplotypes was not observed in either the OHSS case or control populations (Table 4). Two haplotypes (T-C-G, T-C-T) were not detected in the OHSS population, but also occurred at low frequencies $(<5.0 \%)$ in the control population as well. All missing haplotypes were

Table 1 Primer sequences for DNA sequencing

\begin{tabular}{|c|c|c|}
\hline SNP & Forward ( $5^{\prime}$ to $\left.3^{\prime}\right)$ & Reverse $\left(5^{\prime}\right.$ to $\left.3^{\prime}\right)$ \\
\hline rs2219471 & TCCACAGGGATTGCTCCAAC & ATATTTGGCCCCGTGGAGTG \\
\hline rs3025035 & CAGGGGTCCTTGGGAAAGAT & AGAACAGGCCCTACCCTTCT \\
\hline rs2305945 & GTGGGTACTAAGCTATGTAATTCCC & CCACACAGAGCTTGTGGTTTA \\
\hline rs2305948 & TTCCAAGACCATAGCTTACCAT & CAGCATCAGCATAAGAAACTTGTA \\
\hline rs1870377 & TGGTACTGCTAAAAGTCAATGG & GGCTGCGTTGGAAGTTATTT \\
\hline rs1870378 & CACTACGGCCTCAAGAGAGAAG & CTGGGTTCCCAAATGTTATGCG \\
\hline
\end{tabular}


Table 2 SNP frequencies in controls and OHSS cases

\begin{tabular}{|c|c|c|c|}
\hline \multirow[t]{2}{*}{ Variant } & \multicolumn{3}{|c|}{ Frequency } \\
\hline & Total $(n=174)$ & Controls (n - 155) & OHSS Cases $(n=19)$ \\
\hline \multicolumn{4}{|l|}{ rs2305948 } \\
\hline $\mathrm{CC}$ & $131(0.75)$ & $116(0.75)$ & $15(0.79)$ \\
\hline CT & $40(0.23)$ & $36(0.23)$ & $4(0.21)$ \\
\hline$\pi$ & $3(0.02)$ & $3(0.02)$ & 0 \\
\hline \multicolumn{4}{|l|}{ rs 1870378} \\
\hline $\mathrm{CC}$ & $96(0.55)$ & $83(0.54)$ & $13(0.68)$ \\
\hline CT & $65(0.37)$ & $60(0.39)$ & $5(0.26)$ \\
\hline$\pi$ & $13(0.07)$ & $12(0.08)$ & $1(0.05)$ \\
\hline \multicolumn{4}{|l|}{ rs2305945 } \\
\hline GG & $70(0.40)$ & $61(0.39)$ & $9(0.47)$ \\
\hline GT & $79(0.45)$ & $74(0.48)$ & $5(0.26)$ \\
\hline$\pi$ & $25(0.14)$ & $20(0.13)$ & $5(0.26)$ \\
\hline
\end{tabular}

not included in the haplotype-based logistic regression analysis. The rs2305948, rs1870378, rs2305945 (C-T-G) haplotype (unadjusted) was found to be moderately protective $(\mathrm{P}=0.031)$ for OHSS risk $(\mathrm{OR}=0.10 ; 95 \% \mathrm{CI}=$ $0.01,0.80)$ (Table 5). When adjusted for age $(\mathrm{P}=0.020)$, race $(\mathrm{P}=0.023)$ or age/race $(\mathrm{P}=0.011)$, the $\mathrm{C}-\mathrm{T}-\mathrm{G}$ haplotype was significantly associated with decreased OHSS development (Table 6). Additionally, $\mathrm{COH}$ response variables number of follicles $>16 \mathrm{~mm}$ and eggs retrieved were significantly lower in the C-T-G haplotype (See Additional file 4: Table S4 and Additional file 5: Table S5). Only one other haplotype (C-C-T) was significantly associated with an endpoint (fewer follicles $>16 \mathrm{~mm}$ ) (See Additional file 6: Table S6).

\section{Discussion}

The aim of this investigation was to determine whether $K D R$ genetic variation was associated with OHSS risk in $\mathrm{COH}$ patients. We found a novel association between the KDR rs2305948, rs1870378, rs2305945 C-T-G haplotype and reduced risk of developing OHSS. Patients with
Table 4 Haplotype estimation $(n=174)$

\begin{tabular}{|c|c|c|c|c|c|}
\hline \multicolumn{3}{|c|}{ Haplotype } & \multicolumn{3}{|c|}{ Frequency } \\
\hline rs2305948 & rs1870378 & rs2305945 & Total & Control & OHSS Cases \\
\hline C & C & G & 0.352 & 0.334 & 0.474 \\
\hline C & C & $\mathrm{T}$ & 0.327 & 0.329 & 0.342 \\
\hline C & $\mathrm{T}$ & G & 0.164 & 0.185 & 0.026 \\
\hline $\mathrm{T}$ & $\mathrm{T}$ & G & 0.073 & 0.069 & 0.105 \\
\hline $\mathrm{T}$ & C & G & 0.041 & 0.044 & - \\
\hline C & $\mathrm{T}$ & $\mathrm{T}$ & 0.025 & 0.017 & 0.053 \\
\hline $\mathrm{T}$ & C & $\mathrm{T}$ & 0.019 & 0.022 & - \\
\hline $\mathrm{T}$ & $\mathrm{T}$ & $\mathrm{T}$ & - & - & - \\
\hline
\end{tabular}

this haplotype also exhibited decreased ovarian response to $\mathrm{COH}$ (i.e. number of follicles $>16 \mathrm{~mm}$, eggs retrieved). In addition, the rs $2305945 \mathrm{G} / \mathrm{T}$ variant was similarly associated with decreased response to $\mathrm{COH}$ and lower risk of hyperstimulation. These findings are the first to suggest that $K D R$ polymorphisms might serve as predictive genetic biomarkers for ovarian response to $\mathrm{COH}$.

A central component of the pathophysiology of iatrogenic OHSS is increased ovarian VP during $\mathrm{COH}$. The molecular mechanism for increased VP is thought to involve aberrant VEGF signaling [58]. Serum VEGF levels are elevated in OHSS and predictive for OHSS risk [59]. In addition, a VEGFA polymorphism has been as recently identified as a risk allele for OHSS [26]. VEGF-mediated VP is thought to act through KDR-dependent mechanisms and dopamine/dopamine receptor agonists [27,36], which purportedly inhibit KDR function, have shown promise as therapies for OHSS [27,39,42-44]. Interestingly, we observed a moderate association between the (rs2305948/ rs1870378/rs2305945) C-T-G haplotype and lower OHSS risk. Given that the pathophysiology of OHSS involves increased VP, these results suggest that C-T-G haplotype could potentially result in a KDR receptor with decreased function.

The C-T-G haplotype included two intronic SNPs: rs1870378 (in intron 15) and rs2305945 (intron 12). Neither

Table 3 rs2305945 association with OHSS ( $n=174$, Adjusted for Age and Race)

\begin{tabular}{|c|c|c|c|c|c|}
\hline Model & Genotype & Controls & OHSS & OR $(95 \% \mathrm{Cl})$ & P-value \\
\hline \multirow[t]{3}{*}{ Codominant } & $\mathrm{G} / \mathrm{G}$ & 61 (39.4\%) & $9(47.4 \%)$ & 1 & 0.064 \\
\hline & $\mathrm{G} / \mathrm{T}$ & $74(47.7 \%)$ & $5(26.3 \%)$ & $0.35(0.10,1.19)$ & \\
\hline & $\mathrm{T} / \mathrm{T}$ & $20(12.9 \%)$ & 5 (26.3\%) & $1.70(0.46,6.34)$ & \\
\hline \multirow[t]{2}{*}{ Dominant } & $\mathrm{G} / \mathrm{G}$ & 61 (39.4\%) & $9(47.4 \%)$ & 1 & 0.320 \\
\hline & $\mathrm{G} / \mathrm{T}-\mathrm{T} / \mathrm{T}$ & $94(60.6 \%)$ & $10(52.6 \%)$ & $0.59(0.21,1.65)$ & \\
\hline \multirow[t]{2}{*}{ Recessive } & $\mathrm{G} / \mathrm{G}-\mathrm{G} / \mathrm{T}$ & $135(87.1 \%)$ & $14(73.7 \%)$ & 1 & 0.110 \\
\hline & $\mathrm{T} / \mathrm{T}$ & $20(12.9 \%)$ & $5(26.3 \%)$ & $2.79(0.82,9.47)$ & \\
\hline \multirow[t]{2}{*}{ Overdominant } & $\mathrm{G} / \mathrm{G}-\mathrm{T} / \mathrm{T}$ & 81 (52.3\%) & $14(73.7 \%)$ & 1 & 0.027 \\
\hline & $\mathrm{G} / \mathrm{T}$ & $74(47.7 \%)$ & $5(26.3 \%)$ & $0.30(0.10,0.93)$ & \\
\hline
\end{tabular}


Table 5 Haplotype frequencies estimation and association with OHSS $(n=174)$

\begin{tabular}{ccccll}
\hline Haplotype & rs2305948 & rs1870378 & rs2305945 & OR (95\% Cl) & P-value \\
\hline 1 & $\mathrm{C}$ & $\mathrm{C}$ & $\mathrm{G}$ & 1 & - \\
2 & $\mathrm{C}$ & $\mathrm{C}$ & $\mathrm{T}$ & $0.72(0.32,1.59)$ & 0.42 \\
3 & $\mathrm{C}$ & $\mathrm{T}$ & $\mathrm{G}$ & $0.10(0.01,0.80)$ & 0.031 \\
4 & $\mathrm{~T}$ & $\mathrm{~T}$ & $\mathrm{G}$ & $1.15(0.34,3.87)$ & 0.82 \\
5 & $\mathrm{~T}$ & $\mathrm{C}$ & $\mathrm{G}$ & - & - \\
6 & $\mathrm{C}$ & $\mathrm{T}$ & $\mathrm{T}$ & $2.72(0.35,21.30)$ & 0.34 \\
7 & $\mathrm{~T}$ & $\mathrm{C}$ & $\mathrm{T}$ & - & - \\
\hline
\end{tabular}

Global haplotype association p-value: 0.033 .

of these polymorphisms have been associated with disease risk or clinical outcomes. In contrast, the rs2305948 (G > A) variant is a nonsynonymous SNP located in exon 7 that results in an amino acid change from valine to isoleucine (codon 297). It resides in the $\mathrm{NH}_{2}$-terminal portion of the receptor located in the extracellular, ligand-binding domain. In vitro evidence suggests that rs2305948 (G > A) variant decreases KDR binding to VEGF [60]. Clinically, rs2305948 has been associated with increased risk of coronary artery disease [60], intracerebral hemorrhage and stroke recurrence [61]. In addition, the rs2305948 $\mathrm{T}$ allele exists in a haplotype with rs10020464 and rs7692791 that was moderately associated with a lower risk of developing neovascular age-related macular degeneration [62]. However, we found that the rs2305948 C allele in the C-T-G haplotype was associated with decreased OHSS risk. Therefore, the exact role, if any, which the rs2305948 C allele plays in the apparent protection from OHSS provided by the C-T-G haplotype, requires further investigation.

We found only one polymorphism to be moderately associated with OHSS development when corrected for covariates (age, race) known to be independent predictors of OHSS risk $[8,49]$. The rs2305945 G/T genotype was associated with a reduced likelihood of OHSS $(\mathrm{OR}=0.30$; $95 \% \mathrm{CI}=0.10,0.93)$ in an overdominant model. This SNP resides within intron 12 located $\sim 153$ bp downstream of exon 12. It is intriguing that the rs 2305945 genotype and the C-T-G haplotype were associated with both decreased ovarian response and lower risk of OHSS. We postulate

Table 6 Haplotype (CTG) association with OHSS risk

\begin{tabular}{lccc}
\hline Haplotype & OR & $\mathbf{9 5 \% ~ C l}$ & P-value \\
\hline rs2305948 (C), rs1870378 (T), rs2305945 (G) & & & \\
Unadjusted & & & \\
& 0.10 & $0.01,0.80$ & 0.031 \\
Adjusted & & & \\
Age & 0.08 & $0.01,0.66$ & 0.020 \\
Race & 0.08 & $0.01,0.69$ & 0.023 \\
Age, Race & 0.04 & $0.00,0.46$ & 0.011 \\
\hline
\end{tabular}

that rs2305945 SNP could impact KDR mRNA processing and/or stability leading to decreased downstream signaling. However, the precise mechanism by which the G/T heterozygote impacts KDR function requires additional mechanistic studies.

The majority of poor responders to $\mathrm{COH}$ suffer from reduced ovarian reserve [63]. While this study has identified potential protective genetic biomarkers for OHSS, the results are also potentially applicable to identifying patients with diminished ovarian reserve (DOR). To date, there are very few genetic biomarkers for DOR [64-67]. We found that the rs2305945 SNP and the C-T-G haplotype were both associated with diminished ovarian response to $\mathrm{COH}$. It would be interesting to specifically investigate the frequency of these variants in $\mathrm{COH}$ poor responders and/ or patients with DOR. As a result, our results offer promise that $K D R$ polymorphisms might also serve as novel, predictive biomarkers for DOR in $\mathrm{COH}$ patients.

The KDR receptor plays an integral role in ovarian VP and has shown promise as a target for pharmacologic intervention to prevent OHSS. However, there is no information available on the impact of $K D R$ polymorphisms on patient risk of developing OHSS during $\mathrm{COH}$. The results from this preliminary study indicate that $K D R$ polymorphisms are potential predictive biomarkers for OHSS development. We believe this is the first study to link $K D R$ polymorphisms with OHSS risk and decreased ovarian response to $\mathrm{COH}$. A limitation of the study was the small number of OHSS cases available for analysis. The significance of these findings requires validation in a larger, separate population of patients. Given that the variants identified in this study have individually small effect sizes, future work is aimed at uncovering other risk alleles in KDR and other genes implicated in ovarian angiogenesis and VP.

\section{Conclusions}

The KDR receptor plays a central role in VEGFmediated vascular permeability in OHSS and represents a potential target for pharmacologic intervention of OHSS. These results indicate that genetic variation in 
the $K D R$ gene may impact individual risk for developing OHSS from $\mathrm{COH}$. In addition, these results suggest that the rs2305948 variant and C-T-G haplotype may serve as potential biomarkers for diminished response to $\mathrm{COH}$.

\section{Additional files}

Additional file 1: Table S1. Linkage Disequilibrium Analysis ( $D^{\prime}$ statistic).

Additional file 2: Table S2. rs2305945 association with number of follicles in overdominant model $(n=174)$.

Additional file 3: Table S3. rs 2305945 association with number of eggs retrieved $(n=174)$.

Additional file 4: Table S4. Haplotype (CTG) association with large (>16 mm) follicles.

Additional file 5: Table S5. Haplotype (CTG) association with number of eggs retrieved.

Additional file 6: Table S6. Haplotype (CCT) association with large $(>16 \mathrm{~mm})$ follicles.

\section{Abbreviations}

$\mathrm{COH}$ : Controlled ovarian hyperstimulation; OHSS: Ovarian hyperstimulation syndrome; SNP: Single nucleotide polymorphism; VEGFR2: Vascular endothelial growth factor receptor 2; KDR: Kinase insert domain receptor.

\section{Competing interests}

The authors declare that they have no competing interests associated with this work.

\section{Authors' contributions}

TO: Conceived of the study, participated in its design, carried out molecular analyses, assisted in data analysis and drafted the manuscript. PG: Conceived of the study, participated in its design, recruited participants, assisted with drafting the manuscript. AH: Participated in study design, assisted in data analysis and drafted the manuscript. FOS: carried out molecular analysis and assisted in data analysis. DF: Conceived of the study, participated in its design, recruited participants, assisted with drafting the manuscript. TT: carried out molecular analyses and assisted in data analysis. IG: carried out molecular analyses and assisted in data analysis All authors read and approved the final manuscript.

\section{Acknowledgements}

None of the authors have financial conflicts of interest to report. The project described was supported by Award Number UL1RR031988 from the National Center for Research Resources (T.J.O). The content is solely the responsibility of the authors and does not necessarily represent the official views of the National Center for Research Resources or the National Institutes of Health. Funding also provided by a research grant from the Professional Practice Plan and Pharmacy Research Fund, Bernard J. Dunn School of Pharmacy, Shenandoah University.

\section{Author details}

'Department of Pharmacology and Physiology, The George Washington University, Washington, DC, USA. ²Department of Pharmacogenomics, Bernard J. Dunn School of Pharmacy, Shenandoah University, Ashburn, VA, USA. ${ }^{3}$ Center for Neuroscience, Children's National Medical Center, Washington, DC 20010, USA. ${ }^{4}$ Quest Diagnostics, Athena Diagnostics, Worcester, MA 01605, USA. ${ }^{5}$ Department of Obstetrics and Gynecology, The George Washington University, Washington, DC, USA.

Received: 20 March 2014 Accepted: 1 May 2014

Published: 9 May 2014

\section{References}

1. Ficicioglu C, Kutlu T, Baglam E, Bakacak Z: Early follicular antimullerian hormone as an indicator of ovarian reserve. Fertil Steril 2006, 85:592-596.
2. Scott RT, Toner JP, Muasher SJ, Oehninger S, Robinson S, Rosenwaks Z: Follicle-stimulating hormone levels on cycle day 3 are predictive of in vitro fertilization outcome. Fertil Steril 1989, 51:651-654.

3. Licciardi FL, Liu HC, Rosenwaks Z: Day 3 estradiol serum concentrations as prognosticators of ovarian stimulation response and pregnancy outcome in patients undergoing in vitro fertilization. Fertil Steril 1995, 64:991-994.

4. Hsu A, Arny M, Knee AB, Bell C, Cook E, Novak AL, Grow DR: Antral follicle count in clinical practice: analyzing clinical relevance. Fertil Steril 2011, 95:474-479.

5. Alviggi C, Humaidan P, Ezcurra D: Hormonal, functional and genetic biomarkers in controlled ovarian stimulation: tools for matching patients and protocols. Reprod Biol Endocrinol 2012, 10:9.

6. Fiedler K, Ezcurra D: Predicting and preventing ovarian hyperstimulation syndrome (OHSS): the need for individualized not standardized treatment. Reprod Biol Endocrinol 2012, 10:32.

7. Mocanu E, Redmond ML, Hennelly B, Collins C, Harrison R: Odds of ovarian hyperstimulation syndrome (OHSS) - time for reassessment. Hum Fertil 2007, 10:175-181

8. Luke B, Brown MB, Morbeck DE, Hudson SB, Coddington CC 3rd, Stern JE: Factors associated with ovarian hyperstimulation syndrome (OHSS) and its effect on assisted reproductive technology (ART) treatment and outcome. Fertil Steril 2010, 94:1399-1404.

9. Vlahos NF, Gregoriou O: Prevention and management of ovarian hyperstimulation syndrome. Ann N Y Acad Sci 2006, 1092:247-264.

10. Whelan JG 3rd, Vlahos NF: The ovarian hyperstimulation syndrome. Fertil Steril 2000, 73:883-896.

11. Papanikolaou EG, Tournaye H, Verpoest W, Camus M, Vernaeve V, Van Steirteghem A, Devroey P: Early and late ovarian hyperstimulation syndrome: early pregnancy outcome and profile. Hum Reprod 2005, 20:636-641.

12. Ludwig M, Gembruch U, Bauer O, Diedrich K: Ovarian hyperstimulation syndrome (OHSS) in a spontaneous pregnancy with fetal and placental triploidy: information about the general pathophysiology of OHSS. Hum Reprod 1998, 13:2082-2087.

13. Smits G, Olatunbosun O, Delbaere A, Pierson R, Vassart G, Costagliola S: Ovarian hyperstimulation syndrome due to a mutation in the folliclestimulating hormone receptor. N Engl J Med 2003, 349:760-766.

14. Wada I, Macnamee M, Brinsden P: Prevention and treatment of ovarian hyperstimulation. Hum Reprod 1993, 8:2245-2246.

15. Lee TH, Liu CH, Huang CC, Wu YL, Shih YT, Ho HN, Yang YS, Lee MS: Serum anti-Mullerian hormone and estradiol levels as predictors of ovarian hyperstimulation syndrome in assisted reproduction technology cycles. Hum Reprod 2008, 23:160-167.

16. Esinler I, Bayar U, Bozdag G, Yarali H: Outcome of intracytoplasmic sperm injection in patients with polycystic ovary syndrome or isolated polycystic ovaries. Fertil Steril 2005, 84:932-937.

17. Delvigne A, Rozenberg S: Epidemiology and prevention of ovarian hyperstimulation syndrome (OHSS): a review. Hum Reprod Update 2002, 8:559-577.

18. Humaidan P, Quartarolo J, Papanikolaou EG: Preventing ovarian hyperstimulation syndrome: guidance for the clinician. Fertil Steril 2010, 94:389-400.

19. Papanikolaou EG, Pozzobon C, Kolibianakis EM, Camus M, Tournaye H, Fatemi HM, Van Steirteghem A, Devroey P: Incidence and prediction of ovarian hyperstimulation syndrome in women undergoing gonadotropin-releasing hormone antagonist in vitro fertilization cycles. Fertil Steril 2006, 85:112-120.

20. Soares SR, Gomez R, Simon C, Garcia-Velasco JA, Pellicer A: Targeting the vascular endothelial growth factor system to prevent ovarian hyperstimulation syndrome. Hum Reprod Update 2008, 14:321-333.

21. Rizk B, Aboulghar M, Smitz J, Ron-El R: The role of vascular endothelial growth factor and interleukins in the pathogenesis of severe ovarian hyperstimulation syndrome. Hum Reprod Update 1997, 3:255-266.

22. Gomez R, Simon C, Remohi J, Pellicer A: Vascular endothelial growth factor receptor-2 activation induces vascular permeability in hyperstimulated rats, and this effect is prevented by receptor blockade. Endocrinology 2002, 143:4339-4348.

23. McClure N, Healy DL, Rogers PA, Sullivan J, Beaton L, Haning RV Jr, Connolly DT, Robertson DM: Vascular endothelial growth factor as capillary permeability agent in ovarian hyperstimulation syndrome. Lancet 1994, 344:235-236. 
24. Yamamoto S, Konishi I, Tsuruta Y, Nanbu K, Mandai M, Kuroda H, Matsushita K, Hamid AA, Yura Y, Mori T: Expression of vascular endothelial growth factor (VEGF) during folliculogenesis and corpus luteum formation in the human ovary. Gynecol Endocrinol 1997, 11:371-381.

25. Abramov Y, Barak V, Nisman B, Schenker JG: Vascular endothelial growth factor plasma levels correlate to the clinical picture in severe ovarian hyperstimulation syndrome. Fertil Steril 1997, 67:261-265.

26. Hanevik HI, Hilmarsen HT, Skjelbred CF, Tanbo T, Kahn JA: Increased risk of ovarian hyperstimulation syndrome following controlled ovarian hyperstimulation in patients with vascular endothelial growth factor +405 cc genotype. Gynecol Endocrinol 2012, 28:845-849.

27. Soares SR: Etiology of OHSS and use of dopamine agonists. Fertil Steril 2012, 97:517-522.

28. Sugino N, Kashida S, Takiguchi S, Karube-Harada A, Kato H: Expression of vascular endothelial growth factor (VEGF) receptors in rat corpus luteum: regulation by oestradiol during mid-pregnancy. Reproduction 2001, 122:875-881.

29. Sugino N, Kashida S, Takiguchi S, Karube A, Kato H: Expression of vascular endothelial growth factor and its receptors in the human corpus luteum during the menstrual cycle and in early pregnancy. J Clin Endocrinol Metab 2000, 85:3919-3924.

30. Kaczmarek MM, Kowalczyk AE, Waclawik A, Schams D, Ziecik AJ: Expression of vascular endothelial growth factor and its receptors in the porcine corpus luteum during the estrous cycle and early pregnancy. Mol Reprod Dev 2007, 74:730-739.

31. Zimmermann RC, Hartman T, Bohlen P, Sauer MV, Kitajewski J: Preovulatory treatment of mice with anti-VEGF receptor 2 antibody inhibits angiogenesis in corpora lutea. Microvasc Res 2001, 62:15-25.

32. Zimmermann RC, Hartman T, Kavic S, Pauli SA, Bohlen P, Sauer MV, Kitajewski J: Vascular endothelial growth factor receptor 2-mediated angiogenesis is essential for gonadotropin-dependent follicle development. J Clin Invest 2003, 112:659-669.

33. Pauli SA, Tang H, Wang J, Bohlen P, Posser R, Hartman T, Sauer MV, Kitajewski J, Zimmermann RC: The vascular endothelial growth factor (VEGF)/VEGF receptor 2 pathway is critical for blood vessel survival in corpora lutea of pregnancy in the rodent. Endocrinology 2005, 146:1301-1311.

34. Wulff C, Wilson H, Rudge JS, Wiegand SJ, Lunn SF, Fraser HM: Luteal angiogenesis: prevention and intervention by treatment with vascular endothelial growth factor trap (A40). J Clin Endocrinol Metab 2001, 86:3377-3386.

35. Zimmermann RC, Xiao E, Husami N, Sauer MV, Lobo R, Kitajewski J, Ferin M: Short-term administration of antivascular endothelial growth factor antibody in the late follicular phase delays follicular development in the rhesus monkey. J Clin Endocrinol Metab 2001, 86:768-772.

36. Sarkar C, Chakroborty D, Mitra RB, Banerjee S, Dasgupta PS, Basu S: Dopamine in vivo inhibits VEGF-induced phosphorylation of VEGFR-2, MAPK, and focal adhesion kinase in endothelial cells. Am J Physiol Heart Circ Physiol 2004, 287:H1554-1560.

37. Efrati E, Elkin H, Sprecher E, Krivoy N: Distribution of CYP2C9 and VKORC1 risk alleles for warfarin sensitivity and resistance in the Israeli population. Curr Drug Saf 2010, 5:190-193.

38. Alvarez C, Alonso-Muriel I, Garcia G, Crespo J, Bellver J, Simon C, Pellicer A: Implantation is apparently unaffected by the dopamine agonist Cabergoline when administered to prevent ovarian hyperstimulation syndrome in women undergoing assisted reproduction treatment: a pilot study. Hum Reprod 2007, 22:3210-3214.

39. Busso C, Fernandez-Sanchez M, Garcia-Velasco JA, Landeras J, Ballesteros A Munoz E, Gonzalez S, Simon C, Arce JC, Pellicer A: The non-ergot derived dopamine agonist quinagolide in prevention of early ovarian hyperstimulation syndrome in IVF patients: a randomized, double-blind, placebo-controlled trial. Hum Reprod 2010, 25:995-1004.

40. Rollene NL, Amols MH, Hudson SB, Coddington CC: Treatment of ovarian hyperstimulation syndrome using a dopamine agonist and gonadotropin releasing hormone antagonist: a case series. Fertil Steril 2009, 92:1169 e1115-1167

41. Basu S, Nagy JA, Pal S, Vasile E, Eckelhoefer IA, Bliss VS, Manseau EJ, Dasgupta PS, Dvorak HF, Mukhopadhyay D: The neurotransmitter dopamine inhibits angiogenesis induced by vascular permeability factor/ vascular endothelial growth factor. Nat Med 2001, 7:569-574.

42. Shaltout A, Shohyab A, Youssef MA: Can dopamine agonist at a low dose reduce ovarian hyperstimulation syndrome in women at risk undergoing
ICSI treatment cycles? A randomized controlled study. Eur J Obstet Gynecol Reprod Biol 2012, 165:254-258.

43. Youssef MA, van Wely M, Hassan MA, Al-Inany HG, Mochtar M, Khattab S, van der Veen F: Can dopamine agonists reduce the incidence and severity of OHSS in IVF/ICSI treatment cycles? A systematic review and meta-analysis. Hum Reprod Update 2010, 16:459-466.

44. Baumgarten M, Polanski L, Campbell B, Raine-Fenning N: Do dopamine agonists prevent or reduce the severity of ovarian hyperstimulation syndrome in women undergoing assisted reproduction? A systematic review and meta-analysis. Hum Fertil 2013, 16:168-174.

45. Alvarez C, Marti-Bonmati L, Novella-Maestre E, Sanz R, Gomez R, Fernandez Sanchez M, Simon C, Pellicer A: Dopamine agonist cabergoline reduces hemoconcentration and ascites in hyperstimulated women undergoing assisted reproduction. J Clin Endocrinol Metab 2007, 92:2931-2937.

46. Altmae S, Hovatta O, Stavreus-Evers A, Salumets A: Genetic predictors of controlled ovarian hyperstimulation: where do we stand today? Hum Reprod Update 2011, 17:813-828.

47. Binder H, Dittrich R, Hager I, Muller A, Oeser S, Beckmann MW, Hamori M, Fasching PA, Strick R: Association of FSH receptor and CYP19A1 gene variations with sterility and ovarian hyperstimulation syndrome. Reproduction 2008, 135:107-116.

48. Hanevik HI, Hilmarsen HT, Skjelbred CF, Tanbo T, Kahn JA: A single nucleotide polymorphism in BMP15 is associated with high response to ovarian stimulation. Reprod Biomed Online 2011, 23:97-104

49. O'Brien TJ, Kalmin MM, Harralson AF, Clark AM, Gindoff I, Simmens SJ, Frankfurter D, Gindoff P: Association between the luteinizing hormone/ chorionic gonadotropin receptor (LHCGR) rs4073366 polymorphism and ovarian hyperstimulation syndrome during controlled ovarian hyperstimulation. Reprod Biol Endocrinol 2013, 11:71.

50. Gomez R, Gonzalez-Izquierdo M, Zimmermann RC, Novella-Maestre E, Alonso-Muriel I, Sanchez-Criado J, Remohi J, Simon C, Pellicer A: Low-dose dopamine agonist administration blocks vascular endothelial growth factor (VEGF)-mediated vascular hyperpermeability without altering VEGF receptor 2-dependent luteal angiogenesis in a rat ovarian hyperstimulation model. Endocrinology 2006, 147:5400-5411.

51. Navot D, Sandler B: Controlled ovarian hyperstimulation for the new reproductive technologies. Acta Eur Fertil 1989, 20:217-221.

52. Navot D, Margalioth EJ, Laufer N, Birkenfeld A, Relou A, Rosler A, Schenker JG: Direct correlation between plasma renin activity and severity of the ovarian hyperstimulation syndrome. Fertil Steril 1987, 48:57-61.

53. Barrett JC, Fry B, Maller J, Daly MJ: Haploview: analysis and visualization of LD and haplotype maps. Bioinformatics 2005, 21:263-265.

54. International HapMap C: The International HapMap project. Nature 2003, 426:789-796.

55. Sole X, Guino E, Valls J, Iniesta R, Moreno V: SNPStats: a web tool for the analysis of association studies. Bioinformatics 2006, 22:1928-1929.

56. Lin DY, Hu Y, Huang BE: Simple and efficient analysis of disease association with missing genotype data. Am J Hum Genet 2008, 82:444-452.

57. Barrett JC: Haploview: visualization and analysis of SNP genotype data. Cold Spring Harb Protoc 2009, 2009:pdb ip71.

58. Pietrowski D, Szabo L, Sator M, Just A, Egarter C: Ovarian hyperstimulation syndrome is correlated with a reduction of soluble VEGF receptor protein level and a higher amount of VEGF-A. Hum Reprod 2012, 27:196-199.

59. Agrawal R, Tan SL, Wild S, Sladkevicius P, Engmann L, Payne N, Bekir J, Campbell S, Conway G, Jacobs H: Serum vascular endothelial growth factor concentrations in in vitro fertilization cycles predict the risk of ovarian hyperstimulation syndrome. Fertil Steril 1999, 71:287-293.

60. Wang Y, Zheng Y, Zhang W, Yu H, Lou K, Zhang Y, Qin Q, Zhao B, Yang Y, Hui R: Polymorphisms of KDR gene are associated with coronary heart disease. J Am Coll Cardiol 2007, 50:760-767.

61. Zhang W, Sun K, Zhen Y, Wang D, Wang Y, Chen J, Xu J, Hu FB, Hui R: VEGF receptor- 2 variants are associated with susceptibility to stroke and recurrence. Stroke 2009, 40:2720-2726.

62. Fang AM, Lee AY, Kulkarni M, Osborn MP, Brantley MA Jr: Polymorphisms in the VEGFA and VEGFR-2 genes and neovascular age-related macular degeneration. Mol Vis 2009, 15:2710-2719.

63. Pellicer A, Ardiles G, Neuspiller F, Remohi J, Simon C, Bonilla-Musoles F: Evaluation of the ovarian reserve in young low responders with normal basal levels of follicle-stimulating hormone using three-dimensional ultrasonography. Fertil Steril 1998, 70:671-675. 
64. Wang TT, Wu YT, Dong MY, Sheng JZ, Leung PC, Huang HF: G546A polymorphism of growth differentiation factor-9 contributes to the poor outcome of ovarian stimulation in women with diminished ovarian reserve. Fertil Steril 2010, 94:2490-2492.

65. Livshyts G, Podlesnaja S, Kravchenko S, Livshits L: Association of Pvull polymorphism in ESR1 gene with impaired ovarian reserve in patients from Ukraine. Reprod Biol 2013, 13:96-99.

66. Gleicher N, Weghofer A, Oktay K, Barad D: Relevance of triple CGG repeats in the FMR1 gene to ovarian reserve. Reprod Biomed Online 2009, 19:385-390.

67. Livshyts G, Podlesnaja S, Kravchenko S, Sudoma I, Livshits L: A distribution of two SNPs in exon 10 of the FSHR gene among the women with a diminished ovarian reserve in Ukraine. J Assist Reprod Genet 2009. 26:29-34.

doi:10.1186/1477-7827-12-36

Cite this article as: O'Brien et al:: Kinase insert domain receptor/vascular endothelial growth factor receptor 2 (KDR) genetic variation is

associated with ovarian hyperstimulation syndrome. Reproductive Biology and Endocrinology 2014 12:36.

\section{Submit your next manuscript to BioMed Central and take full advantage of:}

- Convenient online submission

- Thorough peer review

- No space constraints or color figure charges

- Immediate publication on acceptance

- Inclusion in PubMed, CAS, Scopus and Google Scholar

- Research which is freely available for redistribution 